\title{
ALGUMAS CARACTERISTICAS DE CURSOS DE GRADUAÇÃO EM ENFERMAGEM OFERECIDOS EM TEMPO PARCIAL: DADOS PARA UMA ANÁLISE DE DEMANDA E EVASÃO*
}

Mizue Ogasawara**

Sônia Cristina lost Pavarini**

\begin{abstract}
RESUMO: Este trabalho teve por objetivo analisar algumas características de cursos particulares de Graduação em Enfermagem do Estado de São Paulo. Utilizou-se um questionário para coletar os dados e os resultados mostraram que os curso de enfermagem em tempo parcial - apesar de pagos - têm uma demanda elevada; as bolsas de estudos oferecidas parecem influenciar na manutenção do aluno na escola; existem oportunidades para o aluno trabalhar e facilidade de acesso ao curso de graduação para os alunos que já atuam na área. Sugere-se que sejam realizados outros estudos com o objetivo de aprofundar a análise em relação à procura pelos cursos de graduação em enfermagem.
\end{abstract}

\begin{abstract}
This paper has the objective of analysing the characteristics of private courses in nursing graduation in the state of São Paulo, as well as its relationship to the demand. A questionary was used to collect the data concemed to the course. The results showed that the part time nursing courses, although being paid for, have a high demand; the scholarships lead to the maintenance of the student in the school, create oportunities for the students to work, and make it easy for those who have already being working in the area access such courses. It is suggested that other studies be carried out in order to establish the causes of such low demand, so that the courses can be developed to attend the needs of the population and keep their level of excellency.
\end{abstract}

UNITERMOS: Curso de Graduação em Enfermagem - Curso em Tempo Parcial Demanda - Evasão

\section{INTRODUÇÃO}

Há atualmente uma preocupação crescente com a procura pelos cursos de enfermagem no Brasil. Como afirmam NAKAMAE e TSUNECHI$\mathrm{RO}\left({ }^{14)}\right.$, durante a década de 70 e até a metade dos anos 80 , a procura pelos cursos de graduação em enfermagem cresceu de forma acelerada. Entretanto, a partir de 1986, observou-se uma reversão dessa tendência. Esta inquietante observação levou à realização do Fórum de Debates - "Ensino e Mercado de Trabalho em Enfermagem", em setembro de 1.988, na Escola de Enfermagem de Ribeirão Preto - USP. Se- gundo NAKAMAE e TSUNECHIRO(14), as discussões, nesse evento, permitiram identificar os seguintes aspectos:

- o baixo ingresso nos cursos foi mais freqüente nos estabelecimentos públicos;

- nos grupos de debates, os representantes de escolas particulares não se mostraram especialmente preocupados com o ingresso, indicando que, no primeiro ano, esses cursos têm as suas vagas preenchidas;

- a evasão ocorre nos primeiros semestres do curso, principalmente nas escolas particulares;

Trabalho apresentado como Tema Livre no $44^{\circ}$ Congresso Brasileiro de Enfermagem. Brasilia-DF, 4 a 9 de outubro de 1992.

** Professoras Assistentes do Departamento de Enfermagem da Universidade Federal de Săo Carlos, SP. 
- há uma tendência de atendentes, auxiliares e técnicos de enfermagem (candidatos que já trabalham) buscarem ascensão social dentro da própria profissão, na maioria, em escolas particulares;

- o vestibular, para o curso de enfermagem, é usado como trampolim para outros cursos.

Em 1990, foi realizado na Escola de Enfermagem de Ribeirão Preto - USP, o workshop "Baixa Procura - Implicações nos Órgãos Formadores"(16). Nesse evento, foram divulgados alguns trabalhos que estavam sendo realizados em relação à essa problemática. O estudo de PEDRAZZANI(15) demonstra o gradativo decréscimo na relação candidato/vaga em vestibulares para o cursos de graduação em enfermagem na década de 80 em 5 (cinco) instituições públicas do Estado de São Paulo. Este fato se acentuou no final da década e a análise estatística projeta para 1992 uma relação menor que um candidato por vaga.

Também foram levantados outros aspectos relacionados a esta problemática, tais como:

- a estrutura do curso é apontada como coadjuvante do problema da baixa procura pelos cursos de graduação em enfermagem, por estes serem, predominantemente, em tempo integral;

- alguns cursos notumos têm preenchido todas as suas vagas;

- dificuldades de os alunos cumprirem as disciplinas nos semestres ou anos previstos;

- mudança da clientela que procura os cursos de graduação em enfermagem.

Diante dos fatos analisados, docentes de algumas Escolas de Enfermagem da Região Sudeste, organizaram-se e propuseram o desenvolvimento de algumas investigações para melhor compreender tal situação e talvez possibilitar a abertura de canais de intervenção nesta realidade.

Especificamente o curso de Enfermagem da Universidade Federal de São Carlos (UFSCar) tem enfrentado, nestes últimos anos, dificuldades para preenchimento de suas vagas.

Conciliando a política de oferecimento de cursos notumos pelas universidades públicas e a sugestão para solucionar a baixa procura para curso de enfermagem, a administração desta entidade estudou a possibilidade de se implantar um curso notumo de enfermagem.

Diante da necessidade de um posicionamento frente a essa proposta, é que partimos para uma investigação junto às Escolas de Enfermagem do Estado de São Paulo, que oferecem cursos em tempo parcial, visto que nos dois eventos citados, os cursos oferecidos em tempo parcial (escolas particulares) não mencionam dificuldades no preenchimento de suas vagas.

Os determinantes da baixa procura pelos cursos de Enfermagem não estão muito claros. É necessário muita investigação para evidenciar e compreender este fenômeno. Assim sendo, de início poderiamos pensar em vários fatores que podem influenciar a opção e a inserção profissional.

A imagem do baixo status social pode ser um determinante. Na década de 50, REZENDE e RIVERA(17) afirmam que há um reconhecimento, pelos jovens, da enfermagem como profisssăo pouco compensadora economicamente. ALCÂNTARA(1) diz que

... o pouco interesse que a enfermagem desperta entre os jovens tem sido explicado através de concepçoes desfavoráveis acerca da profissăo, dada a vinculaçăo do trabalho manual desempenhado predominantemente por pessoas do sexo feminino, de baixo nivel sócio-económico.

Em estudo recente, ALMEIDA(2) confima que

...os calouros do curso revelaram que a enfermagem é pouco reconhecida socialmente [...] podendo constituir-se em causa da evasăo e na baixa procura pelo curso.

MISHIMA(13) também identificou um perfil profissional pouco atrativo para a opçåo pela enfermagem entre os jovens do $2^{\circ}$ grau e cursos preparatórios. Nessa mesma direção SALLUM(18) refere-se que

a imagem da enfermagem percebida pela comunidade goianiense năo é totalmente satisfatória, e esperava-se que - em funçåo das modificaçóes ocomidas em todos os setores da vida social, bem como, a ascensão da profissăo a nivel superior - os estereoti- 
pos tradicionais estivessem menos

presentes.

Outro possivel fator é a desinformação ou má informaçåo da sociedade sobre a profissão e, conseqüentemente, sobre o curso de enfermagem. CARDOSO(7) destaca a falta de informação que os alunos do $3^{\circ}$ ano do $2^{\circ}$ grau apresentam sobre a enfermagem. Vários trabaIhos indicam ser a enfermagem uma profissão predominantemente feminina, o que pode determinar a baixa procura pelo curso. MANZOLLI(10) afima que ...especificamente a enfermagem permanece ainda com a imagem feminina da profissåo, com a grande maioria de mulheres.

$O$ interesse pelos cursos também ocorre, predominantemente, entre as mulheres. ARCU$\mathrm{RI}(5)$, ao caracterizar os ingressantes na Escola de Enfermagem da USP (EEUSP), constatou que a maioria dos alunos é do sexo feminino.

SULLEROT, in SILVA(19), afirma que ... as profissőes tidas como femininas foram continuam sendo menos valorizadas socialmente.

Os próprios profissionais podem influenciar negativamente, ao manifestarem atitudes de insatisfação com a profissão, geradas por desgaste, estresse contínuo, sobrecarga de trabalho assim como má remuneração e falta de prestígio.

MARTINS(11) constatou que entre os fatores analisados existe maior satisfação que insatisfação, entretanto, a integração ao trabalho, destacou-se com ínidice maior de insatisfeitos.

A insatisfação pela profissão parece não ser uma realidade só brasileira. Benson (1986) in ANSELMI(4) verificou em estudo realizado em Wakefield, que as causas do desligamento dos enfermeiros foram: pressões e estresse no trabalho; salários e sistema de benefícios inadequados; baixa qualidade e conflitos na supervisão; conflito entre a administração do hospital, médicos e outras categorias de pessoal; falta de oportunidade para progredir; falta de incentivos de reconhecimento por um bom trabalho; trabaIho cansativo/tedioso; poucas oportunidades para realização profissional; problemas pessoais/familiares e domésticos. Brief (1986) e Prescott e Bowen (1987) in ANSELMI(4) também citam causas desta natureza.

Frente a este contexto, cabe-nos buscar informações para um encaminhamento adequado para a questão da procura pelo curso de Enfermagem na UFSCar.

\section{OBJETIVO}

Analisar algumas características dos Cursos de Graduação em Enfermagem do estado de São Paulo, oferecidos em tempo parcial para subsidiar análises de demanda e de evasão.

\section{PROCEDIMENTO METODOLÓGICO}

A coleta de dados foi feita junto aos cursos de Graduação em Enfermagem do estado de São Paulo, oferecidos em tempo parcial. Elaborou-se um questionário para coletar os dados relativos a estes cursos, tais como: duração, horário de funcionamento, carga horária, índice de evasão, características dos campos de prática, entre outros (Anexo 1).

$O$ instrumento foi entregue aos Diretores e/ou Coordenadores de cursos das escolas, por ocasião do Forum Estadual das Escolas de En-

Quadro 1 - Características de Cursos de Enfermagem das Escolas Particulares que Participam do Estudo. São Paulo, 1992.

\begin{tabular}{|c|c|c|c|c|c|c|c|}
\hline \multirow[t]{2}{*}{ Caracteristicas do Curso } & \multicolumn{7}{|c|}{ ESCOLAS } \\
\hline & A & B & C & D & $\mathrm{E}$ & $\mathbf{F}$ & G \\
\hline Duraçâoo & 4 anos & 4 anos & 4 anos & 4 anos & 4 anos & 4 anos $^{* * \star}$ & 4 anos \\
\hline Carga Horária & $3.690 \mathrm{~h}$ & $2.912 \mathrm{~h}$ & $4.312 \hat{\mathrm{h}}$ & $4.140 \mathrm{~h}$ & $4.500 h^{* \star}$ & $2.700 \mathrm{~h}$ & 3.450 \\
\hline Horário de Funcionamento & $\begin{array}{l}7: 30 \text { às } \\
13: 10 \mathrm{~h}\end{array}$ & manhâ & $\begin{array}{l}7: 20 \text { às } \\
13: 00 \mathrm{~h}\end{array}$ & $\begin{array}{l}7: 00 \text { às } \\
12: 30 \mathrm{~h}\end{array}$ & $\begin{array}{c}7 \text { ass } 13 \mathrm{~h} \\
\text { licenc.: } \\
14 \text { as } 18 \mathrm{~h}\end{array}$ & 7 às $13 \mathrm{~h}$ & 7 as $13 \mathrm{~h}$ \\
\hline $\mathrm{N}^{\circ}$ de Vagas Oferecidas & 80 & 80 & 60 & $50^{*}$ & 60 & 80 & 100 \\
\hline Bolsa de Estudo & poucas & $\operatorname{sim}$ & năo & $\operatorname{sim}$ & 2 tipos & $\operatorname{sim}$ & $\operatorname{sim}$ \\
\hline
\end{tabular}

* a partir de 1993, seráo oferecidas 30 vagas pela Escola D

** com licenciatura

"** até 1991 a duraçăo do curso da Escola F era de 3 anos. A partir de 1992, passou a ser 4 anos. 
Quadro 2 - Vínculo empregatício do aluno segundo a escola. São Paulo, 1992.

\begin{tabular}{|l|c|c|c|c|c|c|c|}
\hline \multicolumn{1}{|c|}{ Características do Aluno } & \multicolumn{9}{|c|}{ ESCOLAS } \\
\cline { 2 - 8 } & $\mathrm{A}$ & $\mathrm{B}$ & $\mathrm{C}$ & $\mathrm{D}$ & $\mathrm{E}$ & $\mathrm{F}$ & $\mathrm{G}$ \\
\hline O aluno trabalha na área de Enfermagem & $\mathrm{X}$ & & $\mathrm{X}$ & $\mathrm{X}$ & $\mathrm{X}$ & $\mathrm{X}$ & $\mathrm{X}$ \\
\hline O aluno trabalha em outra área & & $\mathrm{X}$ & & & $\mathrm{X}$ & & $\mathrm{X}$ \\
\hline
\end{tabular}

fermagem ocorrido em março de 1992, em São Paulo. Para as escolas representadas naquela reunião encaminhou-se pelo correio um ofício juntamente com o questionário. Algumas informações dos cursos noturnos de enfermagem foram coletadas por via telefônica.

O levantamento das escolas que oferecem cursos de Enfermagem e as respectivas localizações foram obtidos através da consulta ao catálogo de cursos do Ministério da Educação e Cultura.

Foram enviados questionários a 18 Escoias de Enfermagem particulares do Estado de São Paulo, das quais 10 (dez) oferecem cursos em período parcial (matutino), 3 (três) em período noturno e 5 (cinco) em período integral. Foram recebidos mas 7 (sete) questionários preenchidos por cursos oferecidos em período parcial matutino.

\section{ANÁLISE E DISCUSSÃO DOS RESULTADOS}

O Quadro 1 mostra as características das escolas consultadas, segundo respostas obtidas junto aos Diretores e/ou Coordenadores dessas instituições.

Constatou-se que, com exceção de uma escola, as demais oferecem bolsas de estudos para os alunos.

Todos os cursos têm, atualmente, a duração de 4 (quatro) anos, variando a carga horária entre 2.700 a 4.500 horas.

A Licenciatura é oferecida por um curso em tempo parcial, no períođo da tarde, em caráter não obrigatório.

Na maioria das escolas é grande o número de vagas, prevalecendo uma média de 80 vagas. Apenas uma escola oferece 50 vagas que serão reduzidas para 30 a partir de 1993.

Não se obteve resposta ao questionário enviado para as 3 (três) escolas que oferecem curso noturno. Sendo de importância para o posicionamento do Departamento de Enfermagem frente à administração da UFSCar quanto à possíveis mudanças nas características do curso, obtivemos, por via telefônica, a informação de que a parte teórica do curso é ministrada nว período noturno e os estágios são realizados

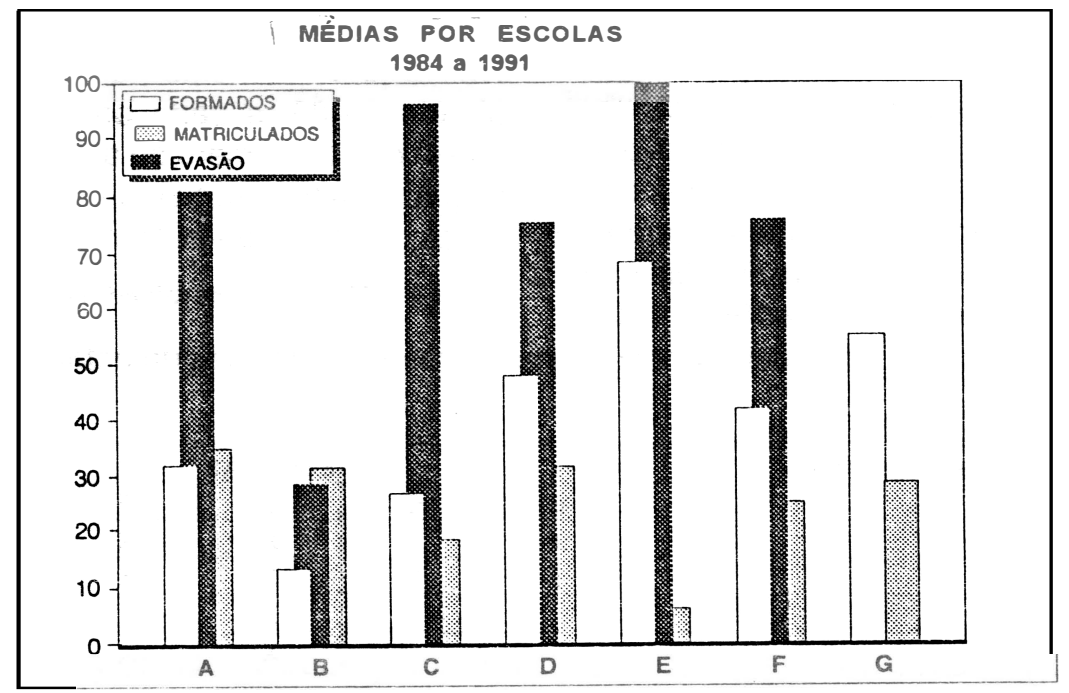

Gráfico 1 - Média de alunos matriculados, de alunos formados e de evasão das escolas de enfermagem em tempo parcial, nos anos de 1984 a 1991. 
nos períodos matutino, vespertino, ou em finais de semana.

Verifica-se no Quadro 2 que os alunos trabalham, predominantemente, na área de enfermagem. Nas Escolas B, E e G existem alunos que trabalham em outras áreas.

É marcante o fato de que em todas as escolas o aluno trabalha. Não verificamos a causa. Entretanto, é evidente que o curso em tempo parcial favorece o trabalho. Com a finalidade de se visualizar a situação do conjunto das escolas, utilizou-se o período de 1984 a 1991, cujos dados foram fornecidos por todas as escolas. Não se sabe o número de ingressantes da escola $G$, uma vez que foi informado apenas o número total de matriculados.

As escolas C e E tiveram $100 \%$ de preenchimento de suas vagas; as escolas $A, D$ e $F$ tiveram entre $74 \%$ e $82 \%$ de suas vagas preenchidas e apenas a escola B teve a procura em torno de $20 \%$.

Um fato bastante evidente é que, apesar de os cursos serem pagos, a procura é alta. Isto pode ser determinado pelo fato de os cursos serem oferecidos em tempo parcial, que por sua vez possibilita ao aluno trabalhar no período da tarde, uma vez que todos os cursos funcionam pela manhã. As bolsas de estudos oferecidas pelas escolas podem contribuir para a manutenção do aluno no curso.

Os dados demonstrados no Gráfico 1 vêm ao encontro à realidade encontrada por BRAN$D^{(6)}$ em escolas privadas do município de São Paulo, e que ofereceram cursos em tempo parcial, no periodo de 1985 a 1989 , os quais tiveram $100 \%$ de suas matrículas efetivadas. BRANDI(6) também verificou que em 2 (duas) escolas públicas (tempo integral) o número de candidatos ao vestibular diminuiu gradativamente e o número de alunos matriculados numa das escolas públicas foi de $50 \%$, ou menos, em 1986, 1988 e
1989.

Na escola de Enfermagem de Ribeirão Preto - USP, segundo MISHIMA, referido por NAKAMAE(14), em 1986, 1987 e 1988, das 80 vagas oferecidas, foram preenchidas 12, 33 e 18 (com re-opção atingiram 33 ingressantes), respectivamente, ou seja, menos que $50 \%$ das vagas.

Também, no Gráfico 1, observa-se que o índice de evasão está em torno de $30 \%$ em 3 (três) escolas (A, B, D). Decresce para $25 \%$ na $F$, para $20 \%$ na escola C e $10 \%$ na escola $E$.

Apesar da procura elevada, a evasão cuja causa não foi identificada neste estudo, ocorre em todas as escolas. Há que se ressaltar a pequena evasão que ocorre naquelas em que se oferece o maior número de bolsas de estudo.

Nas escolas públicas também a evasão está presente ARCURI(5) relata que

...na Escola de Enfermagem da USP, o número de estudantes que abandonou o curso entre 1976 a 1981 foi de $15 \%$ a $17 \%$, destacando 1977 e 1979 , cujo número ultrapassou a $25 \%$ do número de 80 ingressantes, abandono considerado muito alto, principalmente por se tratar de uma escola gratuita.

Nessa escola, KIMURA(9) analisou 44 evasões no período de 1980 a 1983 , as quais ocorreram, predominantemente, nos quatro primeiros semestres, sendo que $44 \%$ dos alunos não chegaram a freqüentar o curso. Ainda nesta instituição, um Grupo de Trabalho sobre Evasão Escolar(8), verificou a tendência crescente da evasão principalmente na segunda metade da década de 80 , a partir dos seguintes pontos: diminuição do número de alunos concluintes em 4 (quatro) anos, aumento do número de desistentes; aumento do número de desligamentos.

$\mathrm{Na}$ pesquisa de BRANDI(6), os índices de

Quadro 3 - Atividades exercidas pelos docentes nas escolas particulares de enfermagem estudadas. São Paulo, 1992

\begin{tabular}{||l|c|c|c|c|c|c|c|}
\hline \multirow{2}{*}{ Atividades que o Docente Desenvolve } & \multicolumn{9}{|c|}{ ESCOLAS } \\
\cline { 2 - 8 } & $\mathrm{A}$ & $\mathrm{B}$ & $\mathrm{C}$ & $\mathrm{D}$ & $\mathrm{E}$ & $\mathrm{F}$ & $\mathrm{G}$ \\
\hline Ensino & $\mathrm{X}$ & $\mathrm{X}$ & $\mathrm{X}$ & $\mathrm{X}$ & $\mathrm{X}$ & $\mathrm{X}$ & $\mathrm{X}$ \\
\hline Pesquisa & & & $\mathrm{X}$ & $\mathrm{X}$ & $\mathrm{X}$ & $\mathrm{X}$ & \\
\hline Extensăo & & & & $\mathrm{X}$ & & & $\mathrm{X}$ \\
\hline Administraçăo & & & & $\mathrm{X}$ & $\mathrm{X}$ & & $\mathrm{X}$ \\
\hline
\end{tabular}


Quadro 4 - Vantagens dos cursos de Enfermagem em tempo pacial, segundo diretores e coordenadores de cursos das escolas. São Paulo, 1992.

\begin{tabular}{|c|c|c|c|c|c|c|c|c|}
\hline \multirow{2}{*}{$\begin{array}{c}\text { Vantagens } \\
\text { Para }\end{array}$} & \multirow[t]{2}{*}{ DESCRIÇĀO DAS VANTAGENS } & \multicolumn{7}{|c|}{ ESCOLAS } \\
\hline & & A & $B^{*}$ & C & D & $\mathbf{E}$ & $\mathbf{F}$ & G \\
\hline \multirow{6}{*}{ O ALUNO } & Possibilita ao aluno trabalhar no período da graduaçăo & $x$ & & $\mathrm{x}$ & $\mathrm{x}$ & $\mathrm{x}$ & & $\mathrm{x}$ \\
\hline & Oportunidade para as pessoas que já atuam na área se graduarem & $\mathrm{x}$ & & & $\mathrm{x}$ & $\mathrm{x}$ & & \\
\hline & Facilita ao aluno que reside em outros municipiose viaja diariamente & & & $\mathrm{x}$ & & & & \\
\hline & Permite o desenvolvimento de atividades extra-curriculares & & & $\mathrm{x}$ & & $\mathrm{x}$ & & \\
\hline & Melhor aproveitamento acadêmico & & & & & $\mathrm{x}$ & & \\
\hline & Diminui o estresse do aluno em relaçăo ao curso em tempo integral & & & & & $\mathrm{x}$ & & \\
\hline \multirow[t]{2}{*}{ O DOCENTE } & $\begin{array}{l}\text { Favorece a possibilidade de estudo, planejamento das atividades e } \\
\text { até mesmo exercer outras atividades profissionais com outros } \\
\text { vínculos empregaticios }\end{array}$ & & & $\mathrm{X}$ & & $x$ & & \\
\hline & $\begin{array}{l}\text { Maior integraçáo com a equipe de enfermagem, mais contexto e } \\
\text { prestaçáo de cuidados aos pacientes pelo fato do estágio ser } \\
\text { realizado das } 7 \text { às } 13 \text { horas, ou seja, durante toda a jornada de } \\
\text { serviço. }\end{array}$ & & & & & $\mathrm{x}$ & & \\
\hline \multirow[t]{2}{*}{ O CURSO } & Minimiza o problema de evasåo que ocorria em tempo integral & & & & & $\mathrm{x}$ & & $x$ \\
\hline & Aumento da procura pelo curso & $\mathrm{x}$ & & & & $\mathrm{x}$ & & \\
\hline
\end{tabular}

* As escolas B e F não relataram nenhuma vantagem.

evasão registrados nas instituições públicas no final da década de 80 foi de $31,2 \%$ em 1986; $30,5 \%$ em 1987 e $40 \%$ em 1988 , em diferentes escolas de enfermagem, índices muito superiores em relação aos $16,9 \%$ e $21,10 \%$ registrados em instituições privadas.

Segundo MIRANDA(12), na Universidade Federal do Rio de Janeiro (UFRJ), a evasão do curso de enfermagem é de $30 \%$. Entre 1986 e 1988 , ocorreram 98 trancamentos de matrícula, sendo que $67 \%$ o fizeram pela primeira vez durante o ciclo básico, $15,3 \%$ não chegaram nem a cursar, $39,8 \%$ trancaram até o $3^{\circ}$ período do curso e $12,3 \%$ após cursar metade do curso.

Os dados obtidos, bem como os já publicados indicam que a questão da evasão é tão preocupante quanto a baixa procura.

ANGELO(3) coloca que

... o risco da evasão de alunos é um problema para a profissão, visto que muitos estudantes ingressam em cursos de enfermagem sem que este seja a sua maior aspiraçăo, e enfrentam dificuldades pessoais e de aprendizagem durante o mesmo, levando um certo número deles ao abandono.

Nesse aspecto, também parece que a problemática não é apenas uma realidade brasileira. Morris e Russo (1979) in ARCURi(5), demonstram a sua preocupação com a elevada taxa de abandono do curso de enfermagem, em Theorafare.
A atividade docente nas escolas particulares que oferecem cursos em tempo parcial se concentra no ensino, como se pode observar no Quadro 3. Os docentes realizam a atividade de pesquisa em 4 das 7 escolas respondentes. A atividade de administração é exercida em 3 das 7 escolas e a atividade de extensão em apenas 2.

Todas as escolas que participaram do estudo oferecem cursos no período matutino e apresentaram 20 vantagens (Quadro 4) e 11 desvantagem para o curso em tempo parcial (Quadro 5).

Quanto às vantagens, 7 contemplam o aluno, sendo as que mais se destacam são: a possibilidade de 0 aluno trabalhar no período de graduação, apontada por 5 escolas; a oportunidade das pessoas que já atuam na área de se graduarem, citada por 3 escolas e a possibilidade de desenvolvimento de atividades extracumiculares referida por 2 escolas, entre outras vantagens.

Quanto às vantagens que contribuem para o curso de enfermagem, foram citadas por 3 escolas, o aumento da procura pelo curso, e por $\hat{1}$ escola a redução do índice de evasão.

Duas escolas apontam como vantagem do curso de enfermagem em periodo parcial, para os docentes, a possibilidade de realizarem atividades relacionadas ao curso como pianejamento, pesquisa, pós-graduação ou outras atividades profissionais não vinculadas ao curso. 
Quadro 5 - Desvantagens dos cursos de Enfermagem em tempo parcial segundo diretores e coordenadores de cursos das escolas

\begin{tabular}{|c|c|c|c|c|c|c|c|c|}
\hline \multirow{2}{*}{$\begin{array}{c}\text { Desvantagens } \\
\text { Para }\end{array}$} & \multirow[t]{2}{*}{ DESCRIÇÃO DAS DESVANTAGENS } & \multicolumn{7}{|c|}{ ESCOLAS } \\
\hline & & A & $\mathrm{B}^{\star}$ & C & $\mathrm{D}$ & E & $\mathrm{F}^{*}$ & G \\
\hline \multirow{5}{*}{ O ALUNO } & $\begin{array}{l}\text { Aproveitamento insatisfatório, em função do aluno exercer outras atividades além do } \\
\text { curso }\end{array}$ & $\mathrm{x}$ & & & & & & \\
\hline & \begin{tabular}{|l|} 
Disponibilidade restrita para o aluno estudar e executar as atividades programadas \\
\end{tabular} & $\mathrm{x}$ & & & & & & $\mathrm{x}$ \\
\hline & $\begin{array}{l}\text { Dificulta o desenvolvimento d eu m espírito universitário, pois em períodos de estágio } \\
\text { as turmas não se encontram }\end{array}$ & & & $x$ & & & & \\
\hline & $\begin{array}{l}\text { Dificulta a freqüencia e uso da biblioteca pelos alunos, principalmente porque há } \\
\text { dificuldade de locomoção cidade-escola }\end{array}$ & & & $x$ & & & & \\
\hline & \begin{tabular}{|l|} 
Dificuldade em realizar pesquisas extra-classe pelos alunos por falta de tempo \\
\end{tabular} & & & & $\mathrm{x}$ & & & \\
\hline \multirow{4}{*}{ O CURSO } & \begin{tabular}{|l|l|} 
Dificulta o desenvolvimento do curso em função de ser classes heterogêneas \\
\end{tabular} & $\mathrm{x}$ & & & $\mathrm{x}$ & & & \\
\hline & $\begin{array}{l}\text { Dificulta as alterações na estrutura curricular, principalmente no acréscimo de } \\
\text { disciplinas e/ou conteúdos programáticos }\end{array}$ & & & $x$ & & & & \\
\hline & Dififuldade na organização de aulas teóricas e estágios & & & & $x$ & & & \\
\hline & $\begin{array}{l}\text { Distância do aluno com os pacientes e a equipe de enfermagem entre } 5^{\mathrm{a}} \text { a } 2^{\mathrm{a}} \text { feiras, } \\
\text { pois os estágios são realizados de } 2^{\mathrm{a}} \text { a } 4^{\mathrm{a}} \text { feiras }\end{array}$ & & & & & $\mathrm{x}$ & & \\
\hline $\begin{array}{l}\text { ADMINISTRA- } \\
\text { ÇĀO DA } \\
\text { ESCOLA }\end{array}$ & $\begin{array}{l}\text { Dificuldade de comunicação geral da Faculdade com os alunos, pois quando iniciam } \\
\text { os estágios eles só vem à escola na } 5^{a} \text { e } 6^{a} \text { feiras }\end{array}$ & & & & & $\mathrm{x}$ & & \\
\hline
\end{tabular}

* As Escolas B e F năo relataram nenhuma desvantagem

Das desvantagens, 5 (cinco) são relacionadas com o desempenho e com o aproveitamento do aluno; 4 (quatro) relativas à organização e ao desenvolvimento do curso e 1 (uma) é relativa à administração da escola.

\section{CONCLUSÕES}

- Os curso de enfermagem em tempo parcial, apesar de pagos, têm uma procura relativamente elevada.

- O oferecimento de bolsas de estudo parece contribuir para a manutenção do aluno na escola.

- O curso em tempo parcial favorece ao aluno a oportunidade de trabalhar.

- O curso em tempo parcial oferece às pessoas que já atuam na área,a oportunidade de sę graduarem.

- Existem mais vantagens que desvantagens na oferta de um curso em tempo parcial.

\section{SUGESTÕES}

- Que sejam realizados outros estudos com o objetivo de esclarecer as características dos cursos de enfermagem em escolas públicas e sua relação com a procura.

- Que sejam realizados novos levantamentos nas demais escolas não incluídas neste estudo.

- Que sejam realizados estudos junto aos alunos para identificar as vantagens e desvantagens do curso em período parcial.

\section{REFERÊNCIAS BIBLIOGRÁFICAS}

1. ALCÂNTARA, G. A enfermagem modema como categoria profissional: obstáculos à sua expansăo na sociedade brasileira. Ribeirăo Preto, 1963. 177p. (Tese). Escola de Enfermagem de Ribeirăo Preto/USP.

2. ALMEIDA, M.L.M. A opçăo pelo curso de enfermagem. In: CONGRESSO BRASILEIRO DE ENFERMAGEM, 41, 1989. Florianópolis, Programa, p.72.

3. ANGELO, M. A escola e o risco da evasăo. Boletim Informativo da Escola de Enfermagem da USP, v.1, n.4, p.1, 1990.
4. ANSELMI, M.L. Porque os enfermeiros deixam o emprego: estudo num hospital-escola. Rev. da Esc. de Enfermagem da USP, v.24, n.2, p.239-250, 1990.

5. ARCURI, E.A.M. et al. Fatores que influenciaram alunos ingressantes na Escola de Enfermagem da USP em 1981, na escola de enfermagem como opçăo profissional. Rev. da Esc. de Enfermagem da USP., v.17, n.1, p.5-10, 1983. 
6. BRANDI, C.M.W. et al. Consideraçס̃es sobre a clientela dos cursos de graduação em enfermagem no municlpio de Săo Paulo. Trabalho apresentado à Câmara Curricular da Escola Paulista de Medicina, SP, 1989.

7. CARDOSO, A.L. O que é o enfermeiro para voce. In: CONGRESSO BRASILEIRO DE ENFERMAGEM, 41, 1989. Florianópolis, 1989. p.103 (mimeo).

8. EVASÃO na Escola de Enfermagem da USP: dados preliminares. Boletim Informativo da Escola de Enfermagem da USP, v.4, n.7, p.9, set. 1988.

9. KIMURA, M. O contexto da evasáo na Escola de Enfermagem da USP. Boletim Informativo da Esc. de Enfermagem da USP, v.4, n.7, p.9-15, set. 1988.

10. MANZOLLI, M.C. et al. Caracterizaçăo do estudante de enfermagem. Enf. Novas Dimensőes, v.3, n.4, p.206214, 1977.

11. MARTINS, C.R. et al. Satisfaçăo do enfermeiro no desempenho profissional. In: CONGRESSO BRASILEIRO DE ENFERMAGEM, 41, 1989. Florianópolis, 1989. p.83.

12. MIRANDA, M.C.L. e SAUTHIER, J. Evasăo: um estudo preliminar. Rev. Bras. de Enfermagem, v.42, n.1/4, p.134-140, 1989.

13. MISHIMA, S.M. A baixa demanda aos cursos de enfermagem: um perfil da profissâo traçado pelos jovens. Ribeirăo Preto: Escola de Enfermagem de Ribeirâo Preto/USP, 1990 (dissertaçăo).
14. NAKAMAE, D.D. e TSUNECHIRO, M.A. Em discussáo o ingresso e a evasáo nos cursos de graduaçăo em enfermagem. Boletim Informativo da Esc. de Enfermagem da USP, v.4, n.6, p.5-11, 1988.

15. PEDRAZZANI, J.C. Perspectivas para a enfermagem: relaçăo candidato/vaga em exames vestibulares. In: Workshop: Baixa Procura - Implicaçర̄es nos Órgâos Formadores. Ribeiráo Preto: Escola de Enfermagem de Ribeirâo Preto/USP, 1990 (mimeo).

16. RELATÓRIO Final do Workshop: Baixa Procura - Implica-çôes nos Órgáos Formadores. Ribeiráo Preto: Escola de Enfermagem de Ribeiráo Preto/USP, abr. 1990.

17. REZENDE, M.A. e RIVERA, S.F. Aceitaçăo da Enfermagem como profissăo. Rev. Bras. de Enfermagem, v.32, n.1, p.75-88, jan/mar 1978.

18. SALUM, M.M.C. A visăo da comunidade sobre o profissional de enfermagem. Rev. Bras. Enf., v.32, n.1, p.75-88, jan/mar 1988.

19. SILVA, G.B. Aspectos sociais da enfermagem. Rev. da Esc. de Enfermagem da USP, v.15, n.2, p.205-210, 1981.

Recebido para publicaçăo em 06.12 .93 


\section{ANEXO 1 ROTEIRO PARA LEVANTAMENTO DE DADOS SOBRE CURSOS DE GRADUAÇÃO EM
ENFERMAGEM E OBSTETRICIA OFERECIDOS EM TEMPO PARCIAL}

Nome da Instituição:

Endereço:

Tel:

Nome da Mantenedora:

Nome do Diretor/Coordenador:

$N^{0}$ de habitantes da região onde está localizada a Escola:

Existem outras Escolas nessa Região?

Quantas:

Característica do Vestibular (próprio, quem organiza, etc)

Ano de início do Curso:

$N^{\circ}$ de vagas:

Houve alteração do período e do $n^{\circ}$ de vagas?

Duração do Curso:

Carga Horária:

Horário do Curso: Horário do Estágio:

Tem serviço de secretaria no período em que funciona o curso?

Existem programas de bolsas de estudo para alunos?

Valor da mensalidade:

\begin{tabular}{|c|c|c|c|c|c|}
\hline \multicolumn{2}{|c|}{ MATRICULADOS } & \multicolumn{2}{|c|}{ FORMANDOS } & \multicolumn{2}{|c|}{ EVASÃO } \\
\hline ANO & $N^{0}$ & ANO & $\mathrm{N}^{0}$ & ANO & $\mathrm{N}^{\circ}$ \\
\hline & & & & & \\
\hline & & & & & \\
\hline & & & & & \\
\hline & & & & & \\
\hline & & & & & \\
\hline
\end{tabular}

Profissão que exercem os alunos:

$\mathrm{N}^{\circ}$ de docentes: Profissionais: Pré-Profissionais:

Humanas e exatas:

Tipo de contrato/docente:

Atividade que exerce: Ensino:

Extensão: Pesquisa:

Administração:

Carga Horária Didática (docente):

Enfoque do Currículo:

A teoria e a prática são concomitantes ou condensados? 
Quais os campos de prática que utiliza:

Creche: Hosp. Geral: (UI, CC, CM, PS, UTI, MI, PED.)

Escola Educ. Infantil: Hosp. Psiquiátrico:

Escola $1^{\circ} \mathrm{grau}$ : Mater/Berç.:

Escola $2^{\circ}$ grau: Asilo:

Posto de Saúde: Centro de Saúde:

Indústrias: Outros:

características dos campos de prática:

$N^{\circ}$ alunos/grupo:

No Docentes:

Tipo de Supervisão:

Porte do Campo Estágio:

Tem estágio fora da cidade?

Neste caso é subsidiado?

Os campos oferecem todas as experiências de aprendizagem?

Opinião dos alunos sobre o curso:

Opinião dos docentes sobre o curso:

Já ministrou outro tipo de Curso de Graduação em Enfermagem? Sim Não Qual:

Avaliação do Curso em tempo parcial, do qual participa:

Vantagens

Desvantagens 